\title{
Changes in occlusal plane through orthognathic surgery
}

\author{
Lucas Senhorinho Esteves' ${ }^{1}$ Carolina Ávila², Paulo José Medeiros ${ }^{3}$
}

Introduction: A conventional ortho-surgical treatment, although with good clinical results, does not often achieve the desired functional outcomes. Patients with dentofacial deformities, especially those with increased occlusal planes (OP), are also affected by muscle, joint and breathing functional disorders, as well as facial esthetic involvement. The surgical manipulation of the OP in orthognathic surgery is an alternative to overcome the limitations of conventional treatment.

Objective: To report the importance of assessing the occlusal plane during diagnosis, planning and ortho-surgical treatment of patients with facial skeletal deformities and its main advantages.

Conclusion: Although both philosophies of ortho-surgical treatment (conventional and by surgical manipulation of the OP) have presented good results, the selective correction of the OP allows a full treatment of these patients, providing better esthetic and functional results.

Keywords: Occlusal plane. Orthognathic surgery. Ortho-surgical treatment.

\footnotetext{
${ }^{1}$ Specialist in Surgery and Bucomaxilofacial Traumatology, Hospital Universitário Pedro Ernesto, UERJ. MSc in Surgery and Bucomaxilofacial Traumatology, UNIGRANRIO.

${ }^{2}$ Specialist in Surgery and Bucomaxilofacial Traumatology, Hospital Universitário Pedro Ernesto, UERJ. MSc in Surgery and Bucomaxilofacial Traumatology, Rio de Janeiro State University.

${ }^{3}$ Chief of Service of Surgery And Bucomaxilofacial Traumatology, Hospital Universitário Pedro Ernesto, UERJ. Full Professor of Surgery, School of Dentistry, UERJ.
}

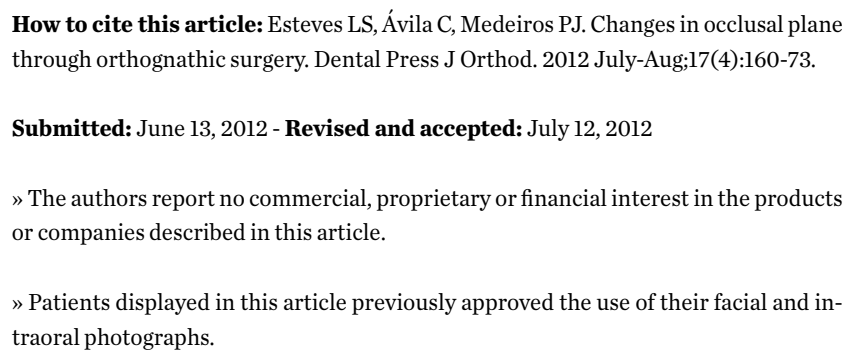

How to cite this article: Esteves LS, Ávila C, Medeiros PJ. Changes in occlusal plane through orthognathic surgery. Dental Press J Orthod. 2012 July-Aug;17(4):160-73.

Submitted: June 13, 2012 - Revised and accepted: July 12, 2012

» The authors report no commercial, proprietary or financial interest in the products or companies described in this article.

» Patients displayed in this article previously approved the use of their facial and intraoral photographs.

Contact address: Lucas Senhorinho Esteves

Rua Eduardo José dos Santos, 147 - Garibaldi, Salvador/BA - Brazil

CEP: 41940-455 - E-mail: lucascirurgia@gmail.com 


\title{
Alteração do plano oclusal na cirurgia ortognática
}

\author{
Lucas Senhorinho Esteves', Carolina Ávila², Paulo José Medeiros ${ }^{3}$
}

Introdução: o tratamento ortocirúrgico convencional, embora apresente bons resultados clínicos, muitas vezes não alcança resultados funcionais desejáveis. Os pacientes com deformidades dentofaciais, principalmente os que possuem plano oclusal (PO) aumentado, são acometidos também por distúrbios funcionais musculares, articulares e respiratórios, além do comprometimento estético facial. A manipulação cirúrgica do PO na cirurgia ortognática é uma alternativa para suprir as limitações do tratamento convencional.

Objetivo: relatar a importância da avaliação do plano oclusal nas fases de diagnóstico, planejamento e tratamento ortocirúrgico de pacientes com deformidades esqueléticas faciais, e suas principais vantagens.

Conclusão: apesar de ambas as filosofias de tratamento ortocirúrgico (convencional e pela manipulação cirúrgica do PO) apresentarem bons resultados, a correção seletiva do PO permite um tratamento integral desses pacientes, propiciando melhores resultados estéticos e funcionais.

Palavras-chave: Plano oclusal. Cirurgia ortognática. Tratamento ortocirúrgico.

${ }^{1}$ Especialista em Cirurgia e Traumatologia Bucomaxilofacial, Hospital Universitário Pedro Ernesto - UERJ. Mestre em Cirurgia e Traumatologia Bucomaxilofacial, UNIGRANRIO.

${ }^{2}$ Especialista em Cirurgia e Traumatologia Bucomaxilofacial, Hospital Universitário Pedro Ernesto - UERJ. Mestre em Cirurgia e Traumatologia Bucomaxilofacial, Universidade do Estado do Rio de Janeiro (UERJ).

${ }^{3}$ Chefe do Serviço de Cirurgia Bucomaxilofacial do Hospital Universitário Pedro Ernesto - UERJ. Professor Titular de Cirurgia da Faculdade de Odontologia da UERJ.
Como citar este artigo: Esteves LS, Ávila C, Medeiros PJ. Changes in occlusal plane through orthognathic surgery. Dental Press J Orthod. 2012 July-Aug;17(4):160-73.

Enviado em: 13 de junho de 2012 - Revisado e aceito: 12 de julho de 2012

» Os autores declaram não ter interesses associativos, comerciais, de propriedade ou financeiros que representem conflito de interesse nos produtos e companhias descritos nesse artigo.

» Os pacientes que aparecem no presente artigo autorizaram previamente a publicação de suas fotografias faciais e intrabucais.

Endereço para correspondência: Lucas Senhorinho Esteves Rua Eduardo José dos Santos, 147 - Garibaldi, Salvador/BA CEP: 41940-455 - E-mail: lucascirurgia@gmail.com 


\section{INTRODUCTION}

The correction of dentofacial deformities usually requires maxillomandibular surgery to obtain good esthetic and functional results. ${ }^{1,2}$ An important cephalometric tool for diagnosis and clinical interrelationship, often neglected in bimaxillary surgery, is the angulation of the occlusal plane (OP).

The occlusal plane is the angle between the Frankfurt horizontal plane and a line touching the cusps of premolars and second molars. The normal value for adults ${ }^{1,3,4}$ is $8 \pm 4^{\circ}$. An increased occlusal plane usually is associated with an open mandibular plane, which also occurs in cases of decreased occlusal planes and closed mandibular planes. ${ }^{1}$

The change in the occlusal plane was initially described for treatment of Class II patients with a decreased mandibular plane. ${ }^{2,5,6}$ Since then, other types of dentofacial deformities have been treated by surgical modification of the occlusal plane, proving longterm stability and confirming the described functional and esthetic benefits.

One of the biggest advantages of using this tool is the possibility of modifying patients' facial pattern from brachycephalic and dolichocephalic to mesocephalic - which is not possible without the manipulation of the OP. In conventional treatment plans, usually the change in the OP was an inevitable consequence when conducting any maxillary vertical modification allowing for mandibular autorotation. ${ }^{1,6,7,8}$ However, even when we could achieve a good occlusion in centric relation, it was not possible to obtain an optimal inter-relationship between esthetics and function of musculoskeletal and dental structures. ${ }^{1,6,7,9}$ Thus, the selective alteration of the occlusal plane allows the maxillofacial surgeon to reestablish the correct and proper jaw function with respect to the cranial base and, consequently, better esthetic results in patients with dentoskeletal deformities. ${ }^{1,5,6}$

This article will discuss the basics of orthodontic treatment and surgical management of patients with deformities that require selective alteration of the occlusal plane.

\section{Occlusal plane $x$ facial type}

There are two types of facial pattern suitable for the selective alteration of the OP: Patients with high occlusal plane (dolichocephalic) and those with low occlusal plane (brachycephalic).

\section{High occlusal plane - dolichocephalic patients}

The basic characteristics of this type of patient are: 1) increased occlusal plane $\left.\left(>12^{\circ}\right), 2\right)$ increased mandibular plane, 3) anterior vertical maxillary excess and / or posterior vertical maxillary deficiency, 4) increased lower anterior face height (LAFH) and / or decreased mandibular vertical ramus; 5) anteroposterior (AP) pogonion deficiency, 6) AP mandibular deficiency; 7) lingually displaced upper incisors, which may allow labial displacement, 8) lingually displaced lower incisors, 9) Class II malocclusion, also occurring in Class I or III, 10) anterior open bite, 11) obstructive sleep apnea from moderate to severe due posterior displacement of the tongue as well as constriction of the throat, in most severe cases (Fig 1).,4

\section{Surgical decrease of the occlusal plane: Counterclock- wise rotation of the maxillomandibular complex}

With the surgical decrease of the occlusal plane, the following changes occur: 1) reduction of the occlusal plane angulation, 2) reduction of the mandibular plane angulation, 3) buccal inclination of maxillary incisors, 4) decrease of lower incisor inclination (lingual); 5) greater pogonion projection in relation to the lower incisors, 6) clinical definition of mandibular angle projection, 7) increase in posterior facial height, 8) normalization of LAFH, 9) tendency of posterior movement of the paranasal region, 10) upper airway increase, around $40 \%$ of the amount of mandibular advancement (Fig 2-5), ${ }^{1,4}$

The choice for the center of rotation influences directly the postoperative facial esthetics. When using the incisal edge of the upper incisors as a fixed point for the counterclockwise rotation of the occlusal plane, the tendency is for a posterior movement of the paranasal region to occur. In contrast, when this center is fixed at point $\mathrm{A}$, the effect is smaller in the paranasal region. However, the inclination of the upper incisors increases, followed by the projection of the upper lip and pogonion. ${ }^{1,3,6,7}$ These clinical implications are important at initial planning, aiming at satisfactory esthetic results for patients.

\section{Low occlusal plane - brachycephalic patients}

The basic characteristics of this type of patients are: 1) decreased occlusal plane $(<4), 2$ ) decreased mandibular plane, 3) increased projection of the pogonion; 


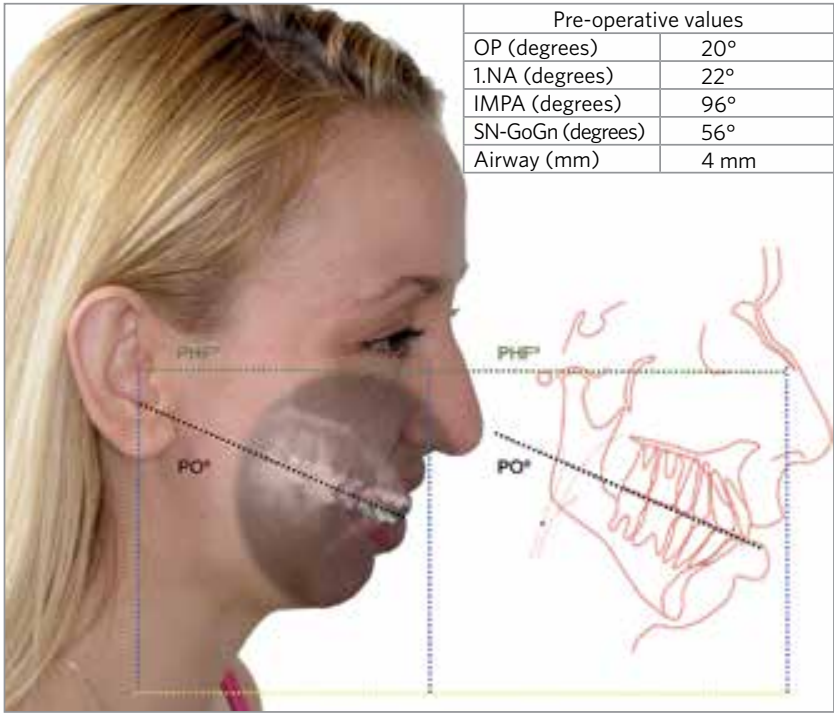

Figure 1 - Clinical and cephalometric correlation: High occlusal plane. Note that the horizontal overbite is incompatible with the facial deformity.

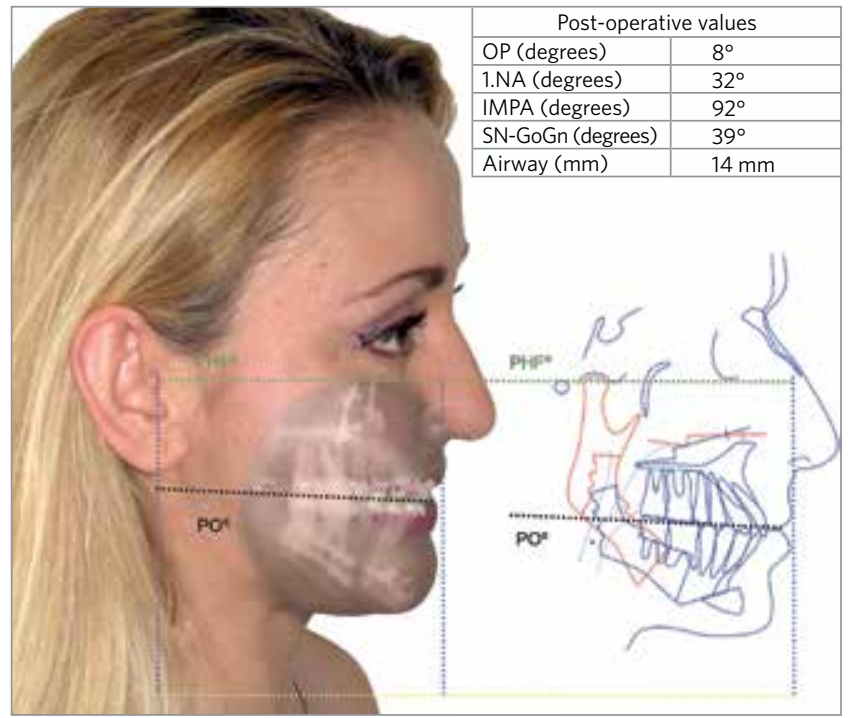

Figure 2 - Clinical and cephalometric correlation: Surgical correction of the occlusal plane after counterclockwise rotation of the maxillomandibular complex.

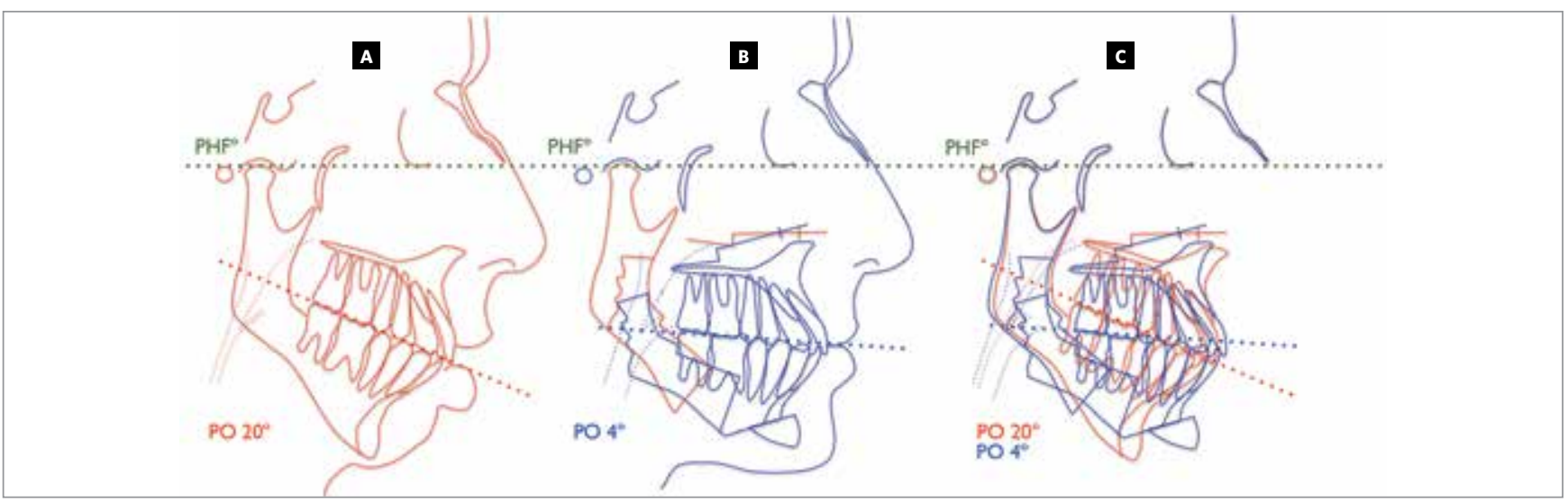

Figure 3 - Cephalometric tracings: A) Pre-operative; B) Post-operative; C) Pre-and post-operative tracing overlays, with the respective OP values.
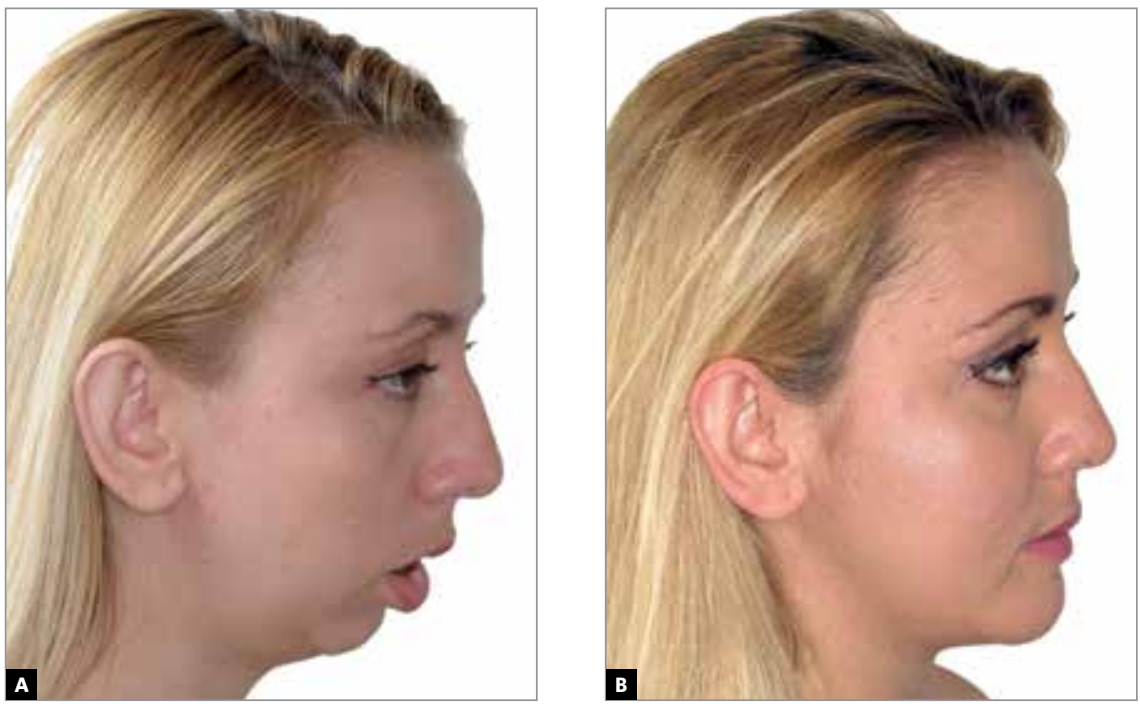

Figure 4 - Profile Clinical Images: A) pre-operative; B) post-operative.

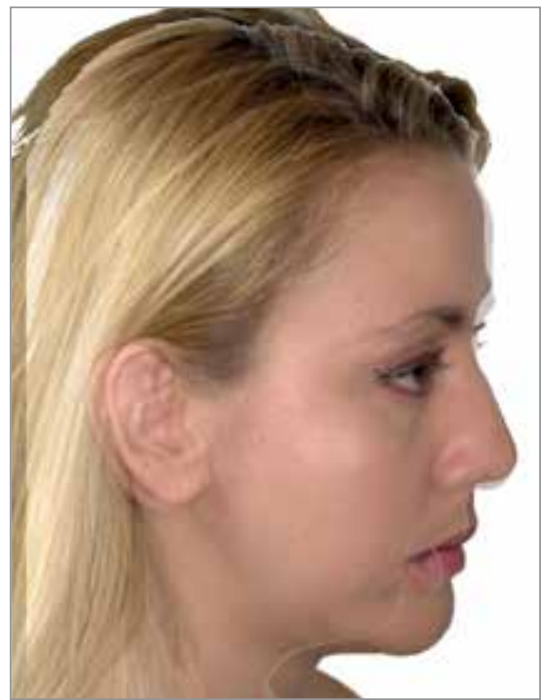

Figure 5 - Overlays of clinical images pre and post-operative. 
4) clinically well defined mandibular angles, 5) decreased inclination of the upper incisors, which may occur also with increased inclination, 6) decreased inclination of the lower incisors; 7) Class II malocclusion, but can occur with Class I or III, 8) anterior overbite, 9) accentuated lower curve of Spee and eventually reverse upper curve of Spee (Fig 6). ${ }^{1,4}$

\section{Surgical increase of the occlusal plane: Clockwise rotation of the maxillomandibular complex}

With the surgical increasing of the occlusal plane, the following changes occur: 1) increased angulation of the occlusal plane, 2) increased angulation of the mandibular plane, 3) decreased inclination of upper incisors, 4) increased inclination of lower incisor; 5) posterior rotation of the pogonion, 6) posterior facial height reduction, 7) advancement of the paranasal region (Fig 7-10).,1,45

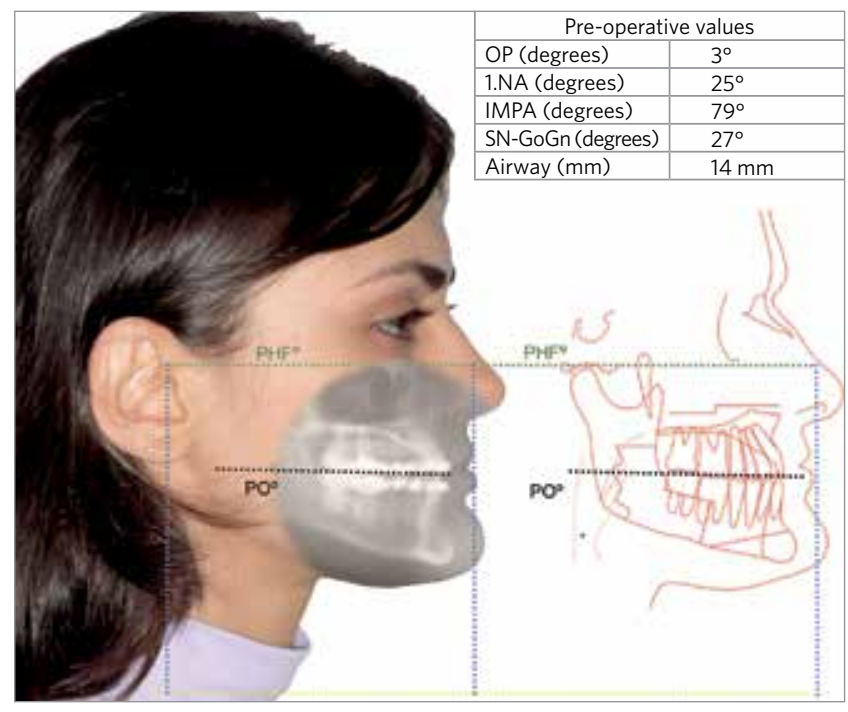

Figure 6 - Clinical and cephalometric correlation: Low occlusal plane. Note that the horizontal overbite is incompatible with the facial deformity.
As in the maxillomandibular counterclockwise rotation, the anatomical center of rotation also significantly interferes in the esthetic changes promoted by the clockwise rotation of the OP. When using the incisal edge of the upper incisors as a fixed point, there will be major repercussions in the paranasal region, due to their advancement. In contrast, if the center is the A point, the paranasal region will not be affected significantly, but the inclination of the upper incisors will decrease, resulting in posterior movement of the upper lip., ${ }^{1,3,5,6,7}$

\section{Pre-surgical orthodontic objectives}

As previously mentioned, the surgical modification of the OP directly interferes in the inclination of upper and lower incisors. ${ }^{1}$ Based on this fact, the orthodontic treatment objectives should be established bearing in mind all the repercussions that will

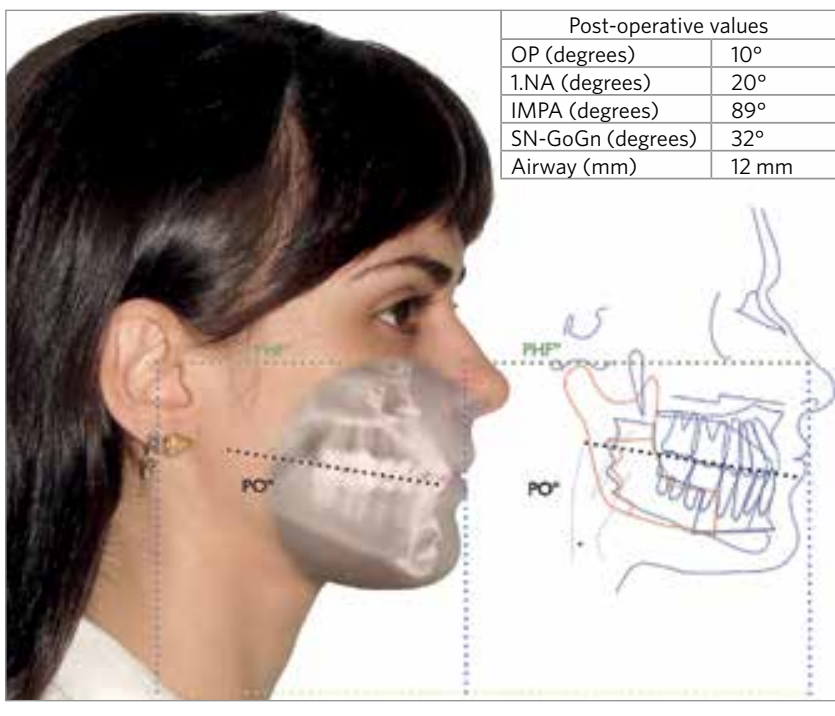

Figure 7 - Clinical and cephalometric correlation: Surgical correction of the occlusal plane after clockwise rotation of the maxillomandibular complex.

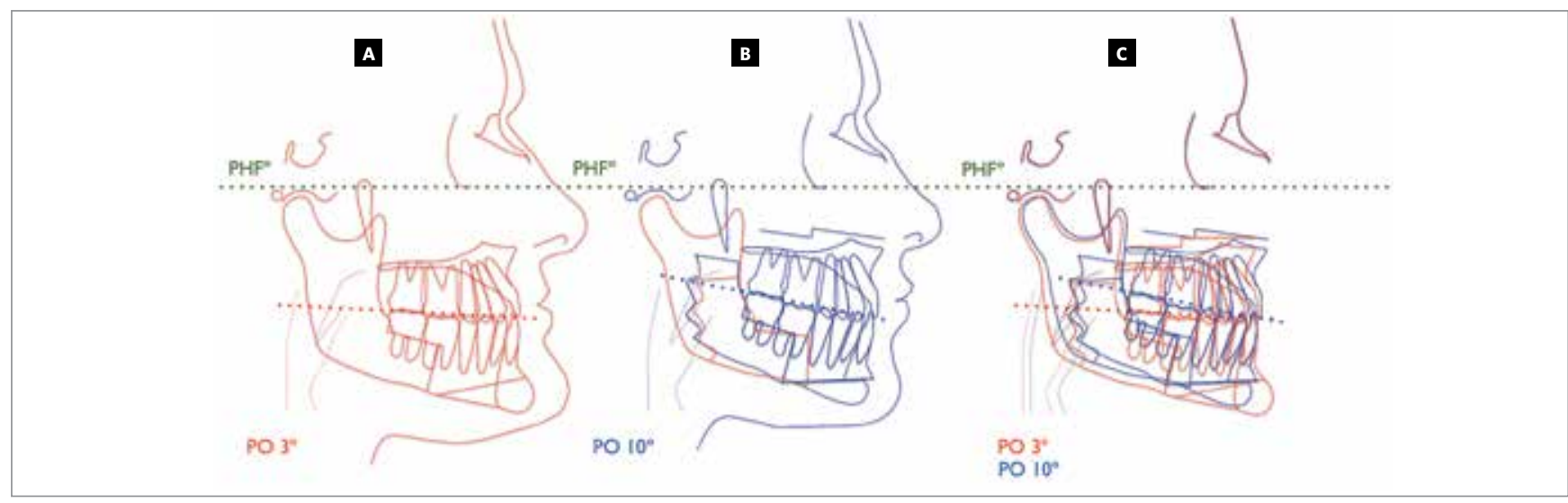

Figure 8 - Cephalometric tracings: A) pre-operative; B) post-operative; C) pre- and post-operative tracing overlays, and respective OP values. 


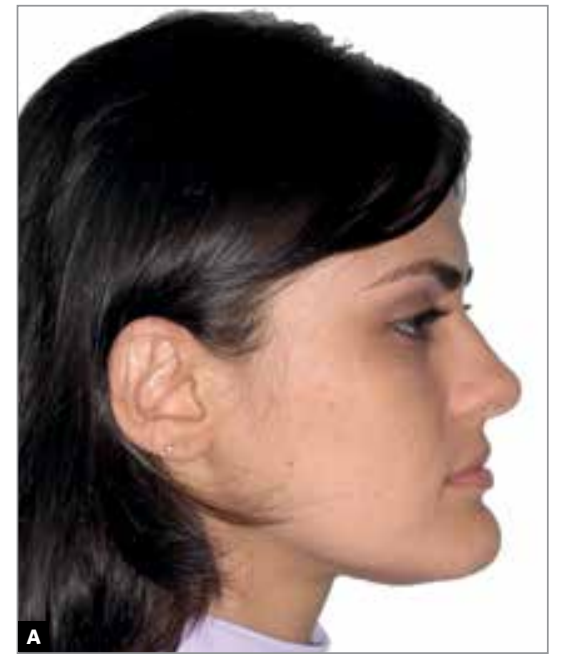

Figure 9 - Profile clinical images: A) pre-operative; B) post-operative.

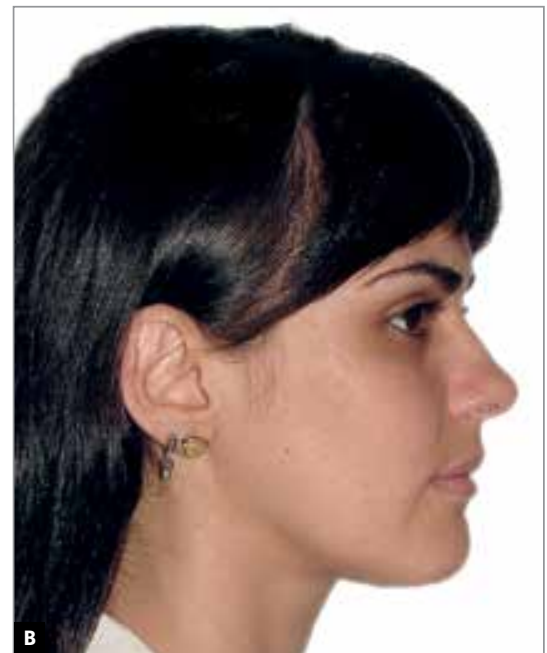

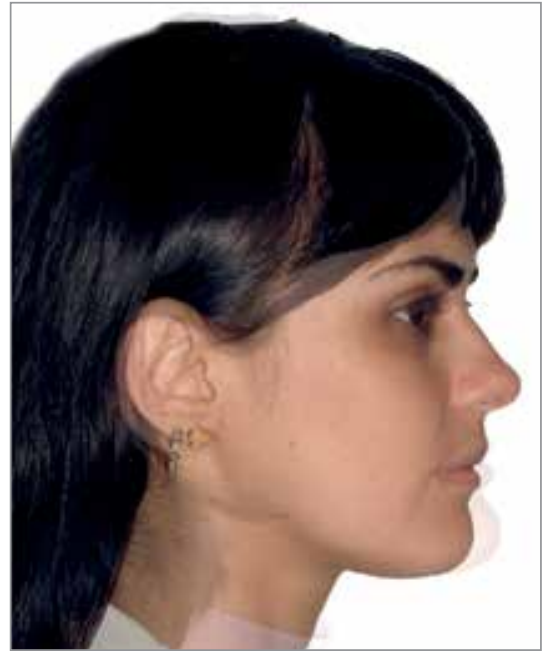

Figure 10 - Clinical images overlays. occur after surgery in the dental arches, in the face and especially in the incisors. Orthodontics should be directed to compensate this movement, which will occur and avoid displeasing surgical results. ${ }^{4,5,8}$ At this point, a good relation between orthodontist / surgeon becomes fundamental, so that they can perform together the ortho-surgical planning.

In patients with a high occlusal plane, in which the rotation of the maxillomandibular complex in a counterclockwise direction will be performed, the buccal inclination of the upper incisors and the uprighting of the lower incisors tends to occur. Thus, it is desirable that during orthodontic treatment, there is a decrease in the inclination of the upper incisors, with lingual torque of their crowns lower than the ideal, as well as the buccal torque of the lower incisors greater than normal, so that its axial inclination be corrected during surgery by reducing the OP. ${ }^{1,4,8}$

In patients with low occlusal plane, an increase in the inclination of the upper incisors would be indicated, because of its buccal movement during the preoperative phase of orthodontics. Among the pre-surgical orthodontic objectives is also included the reduction of the lower incisor angle with lingual torque of their crowns. Due to the clockwise surgical alteration and consequent increase in the OP, there will be in equal proportion, a decrease in the angulation of the upper incisors and an increase in lower incisor inclination, returning these measures to an ideal value., ${ }^{1,4}$ These orthodontic guidelines described for inclination of the upper incisors become higher when maxillary surgical segmentation is performed. This is because when segmenting the maxilla between lateral incisors and canines, there is the possibility of modifying the torque of the tooth-bone segment so the inclination of the previous teeth is normalized. . $^{1,4,5,8}$

The determination of pre-surgical orthodontic objectives has significant influence on knowing when the extraction of premolars will be required; when the curves of Spee, pronounced or reverse, will be leveled orthodontically or surgically; and when intra-arch orthodontic procedures are necessary to obtain adequate tooth positions.

\section{CASE REPORTS}

\section{High occlusal plane - dolichocephalic patient}

Male patient, 20 years-old, with the chief complaint of occlusal disharmony and elongated face.

In the facial clinical examination, a long face pattern III was observed, symmetrical, increased lower anterior face height (LAFH), paranasal deficiency, good nasal support, reversed interlabial relation, gingival smile and lip incompetence. The intraoral clinical examination showed a Class III dental relationship for molars and canines, with upper and lower crowding (Fig 11).

The cephalometric analysis confirmed the clinical impression, showing a skeletal Class III, characterized by an anteroposterior deficiency of the maxilla and maxillomandibular clockwise growth, with an increased occlusal plane. The upper and lower incisors were well positioned (Fig 12A). 
The chosen treatment plan was the ortho-surgical correction of dentofacial deformity, aiming apart from the malocclusion correction, also the facial pattern modification by surgical alteration of the occlusal plane in a counterclockwise direction (Fig 12B).

The patient underwent orthodontic treatment with the preparation of the dental arches for orthognathic surgery. Alignment, leveling and decompensation of the axial inclinations without dental extractions were conducted. The sequence of orthodontic treatment and surgery is shown in Figures 13-19.

\section{Low occlusal plane - brachycephalic patients}

Female patient, 19 years-old, with the main complaint of occlusal disharmony, the smile and speech deficiency.

In the facial clinical examination, a Pattern III face was observed, mandibular asymmetry, paranasal deficiency and poor nasal support. The clinical examination
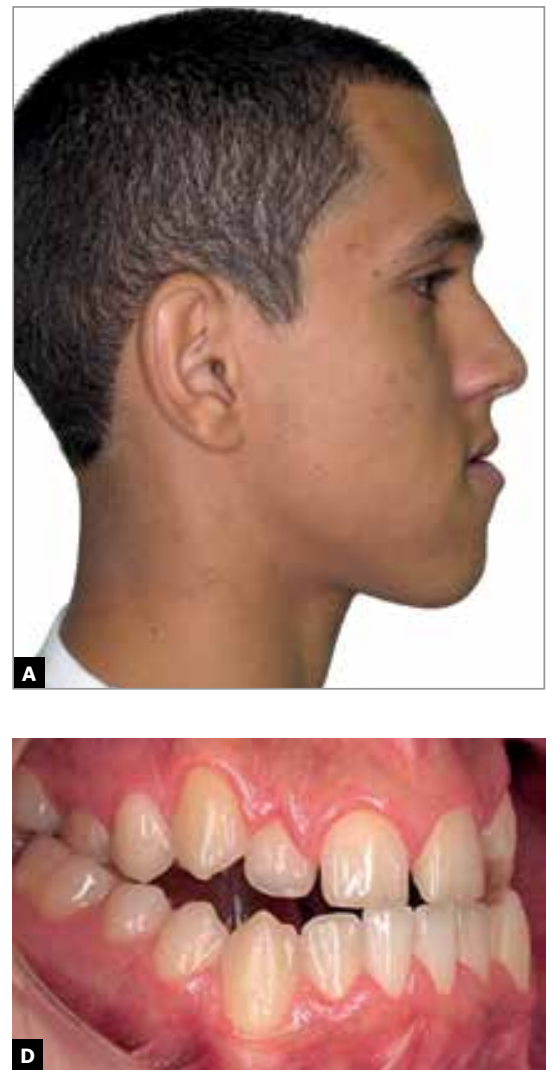
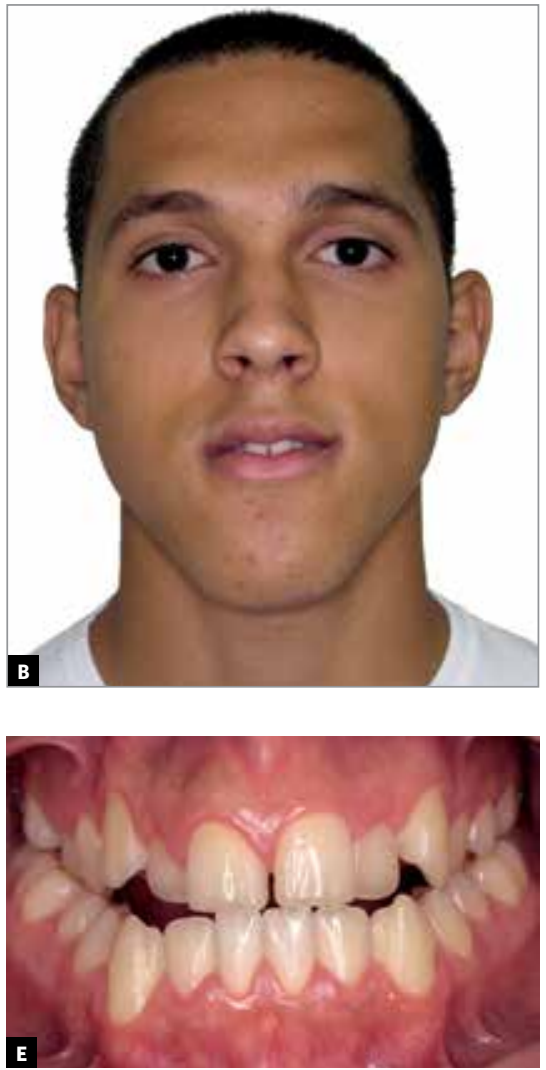
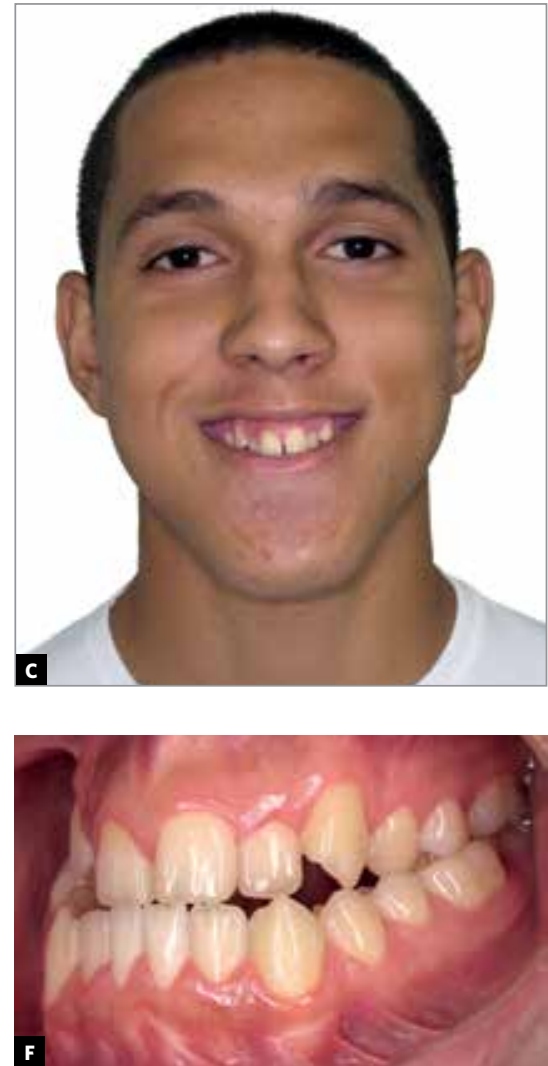

Figure 11 - A, B, C) Initial facial clinical aspect. D, E, F) Intraoral initial images.

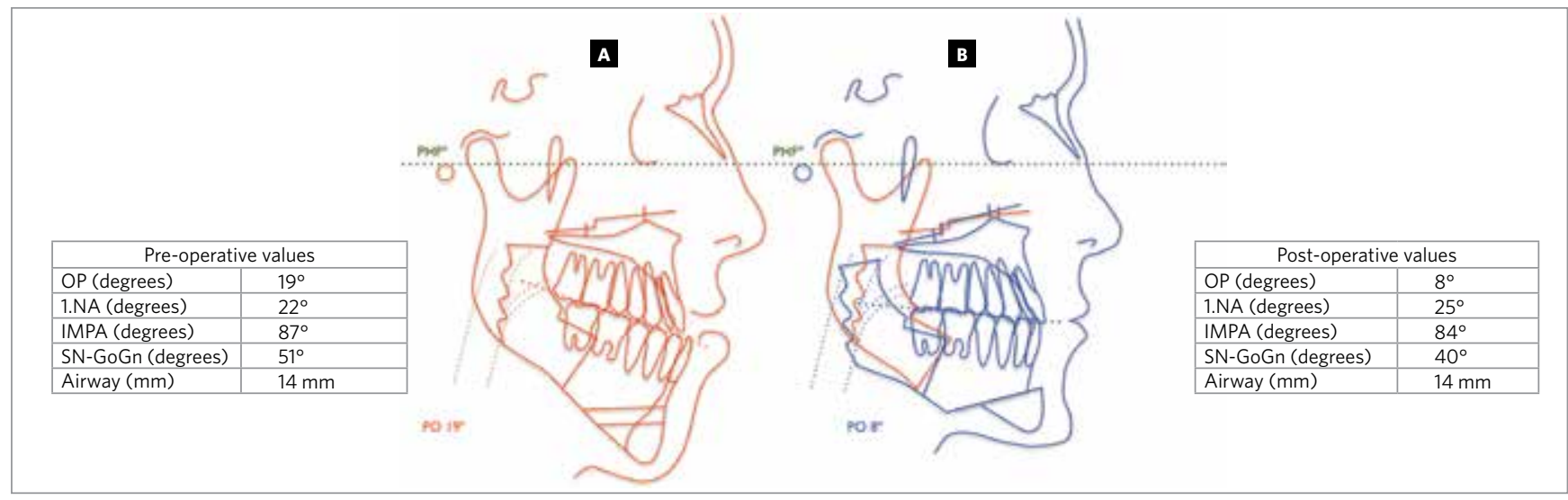

Figure 12 - Surgical correction of the occlusal plane after counterclockwise rotation of the maxillomandibular complex. A) Pre-operative cephalometric tracing; B) post-operative cephalometric tracing. 

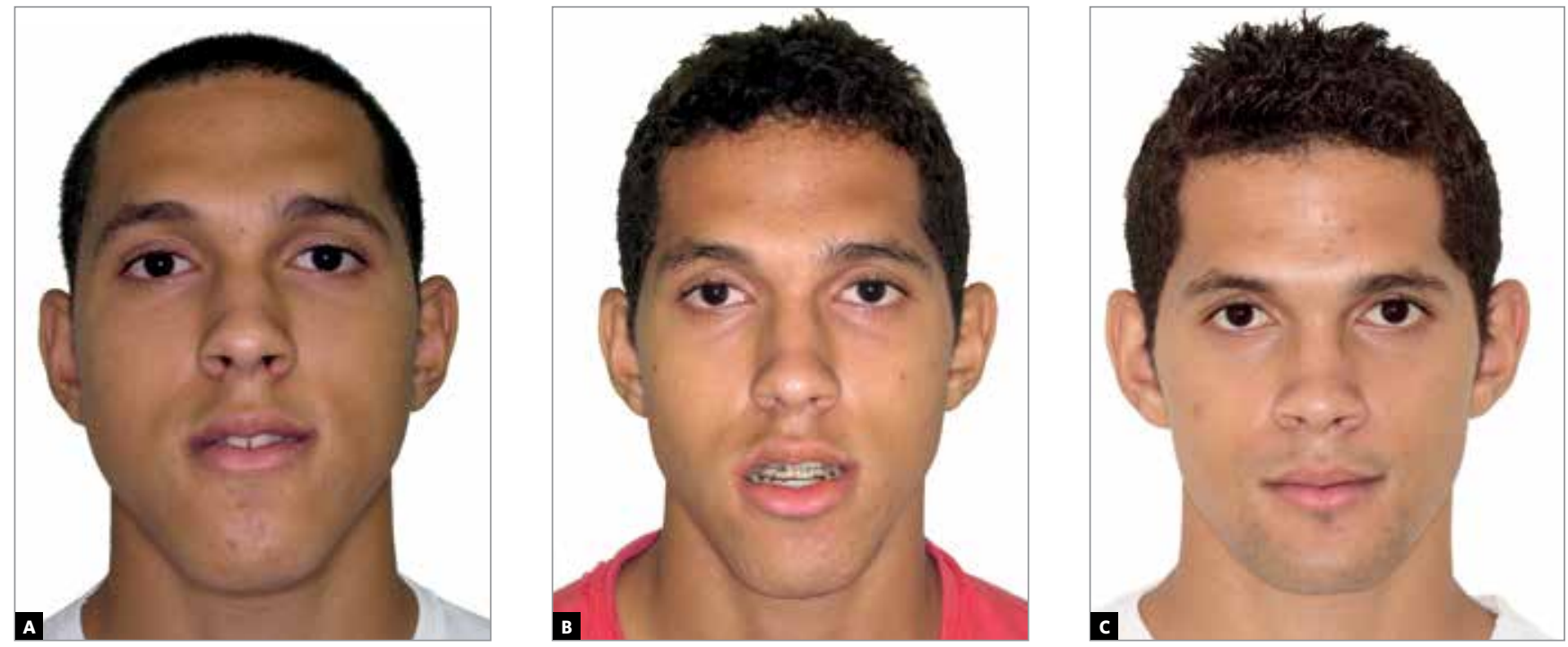

Figure 13 - Frontal facial clinical follow up with lips at rest: A) Initial, B) pre-operative and C) post-operative.
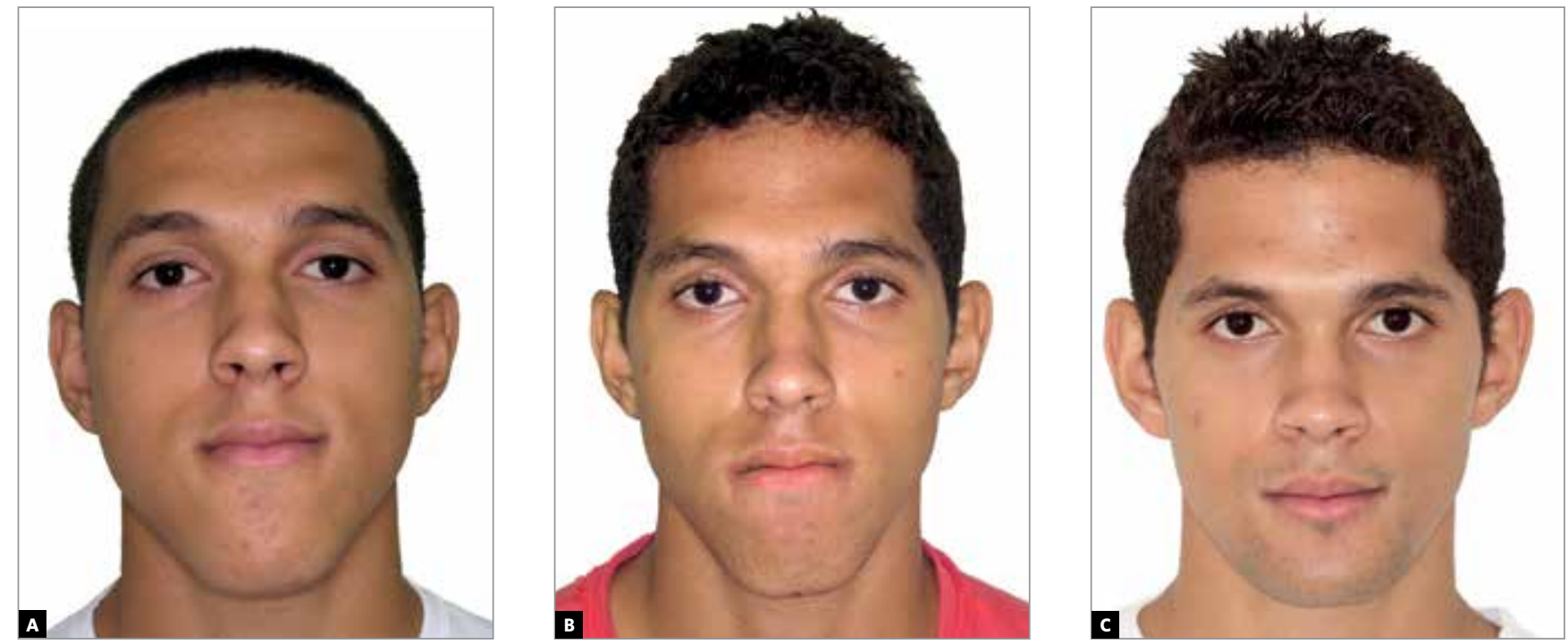

Figure 14 - Frontal facial clinical follow up with sealed lips: A) Initial, B) pre-operative and C) post-operative.
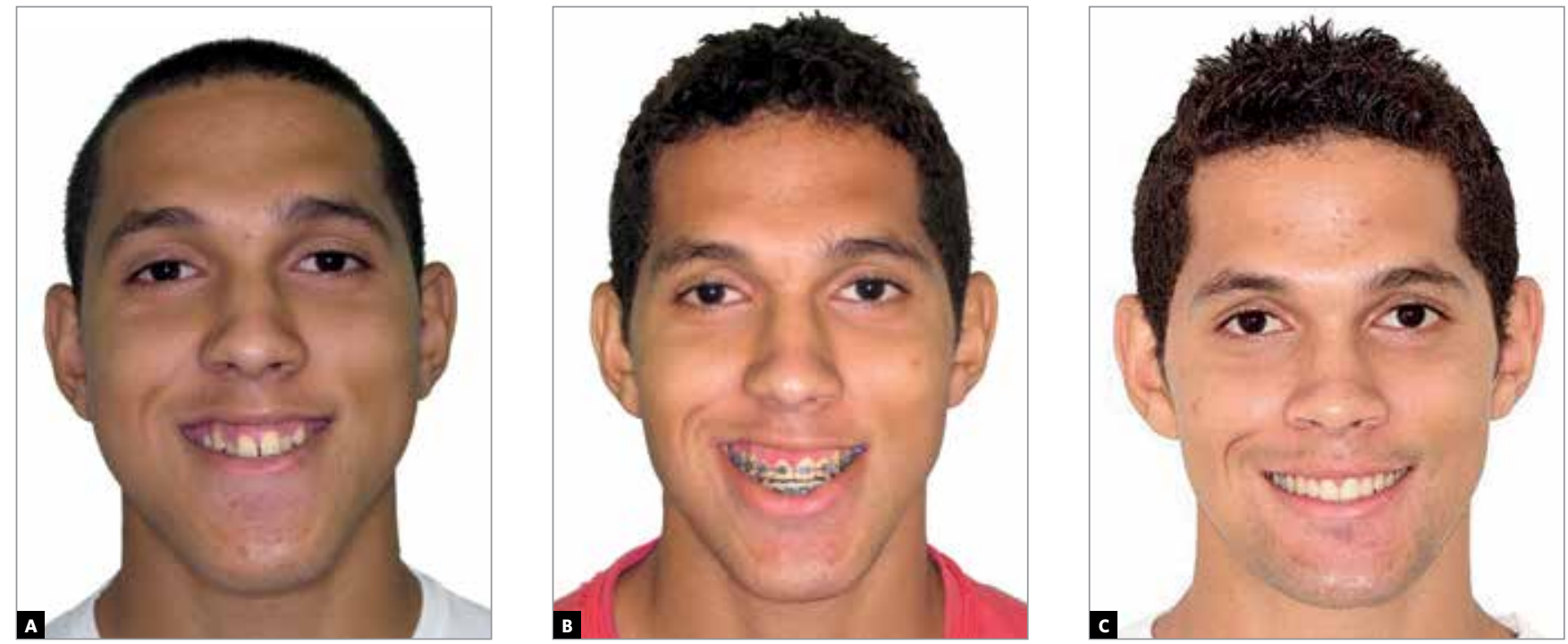

Figure 15 - Frontal facial clinical follow up smiling: A) Initial, B) pre-operative and C) post-operative. 

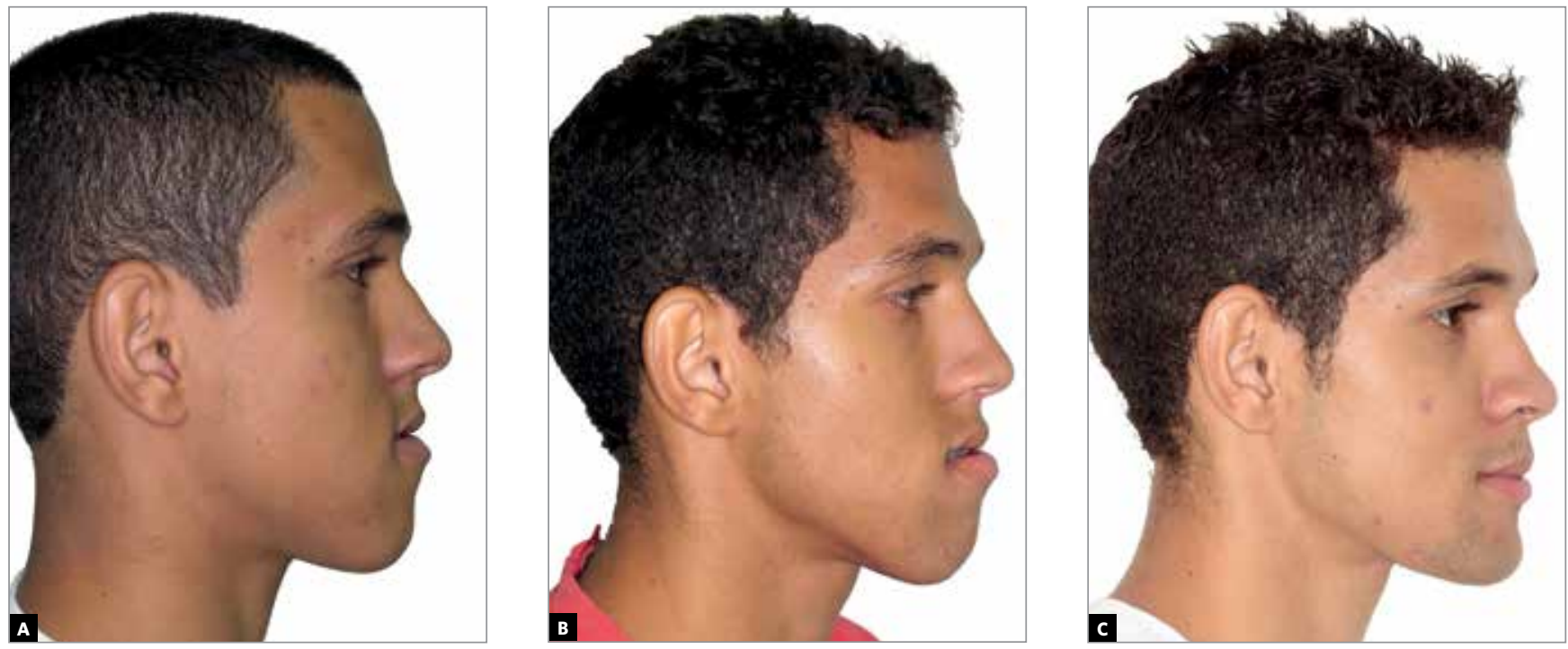

Figure 16 - Clinical follow up of facial profile with lips at rest: A) Initial, B) pre-operative and C) post-operative.
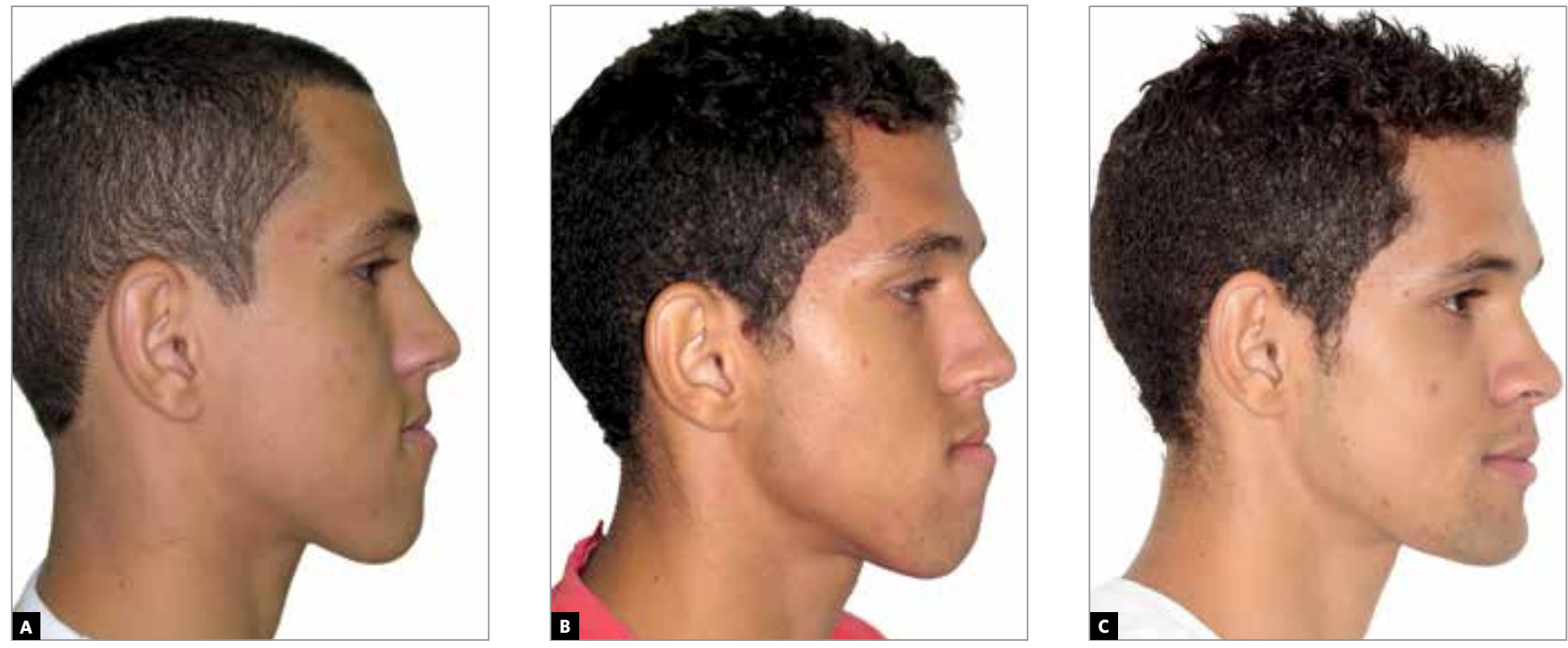

Figure 17 - Clinical follow up of facial profile with sealed lips: A) Initial, B) pre-operative and C) post-operative.
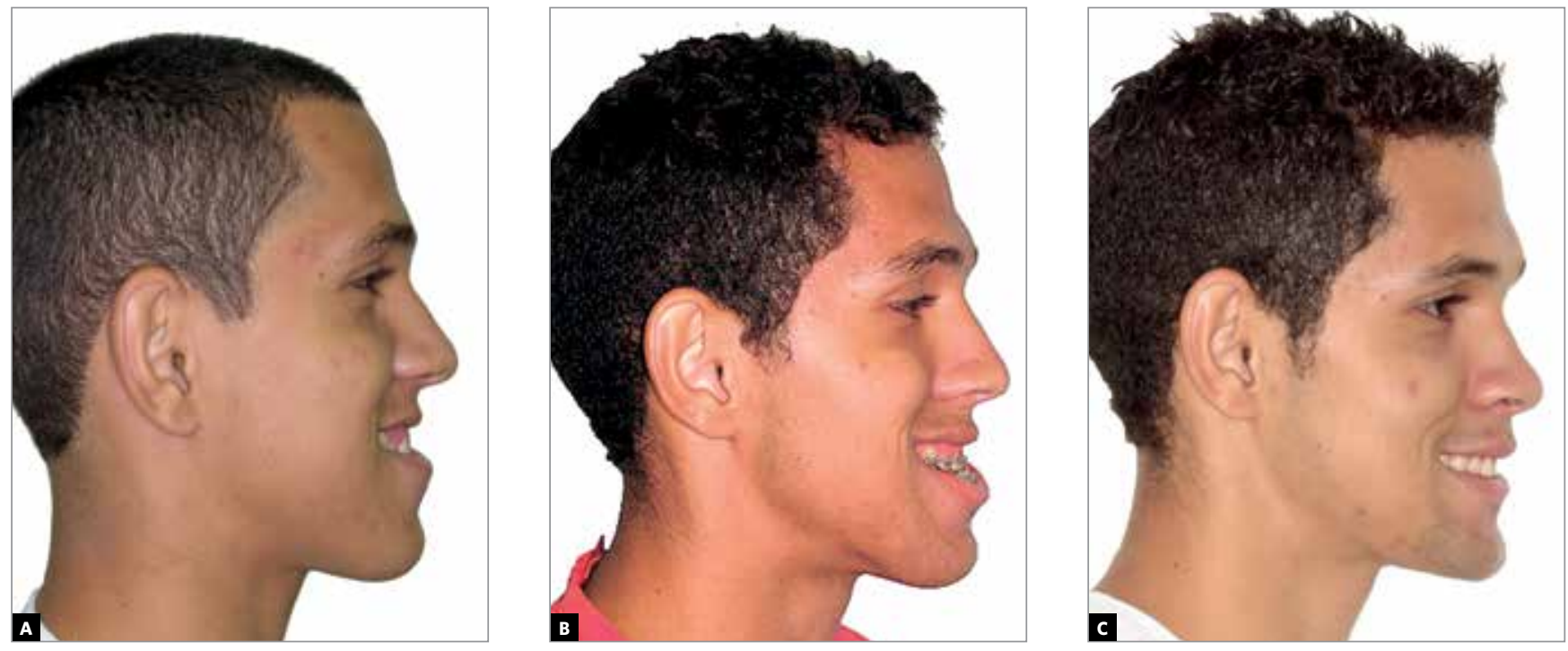

Figure 18 - Clinical follow up of facial profile smiling: A) Initial, B) Pre-operative and C) post-operative. 

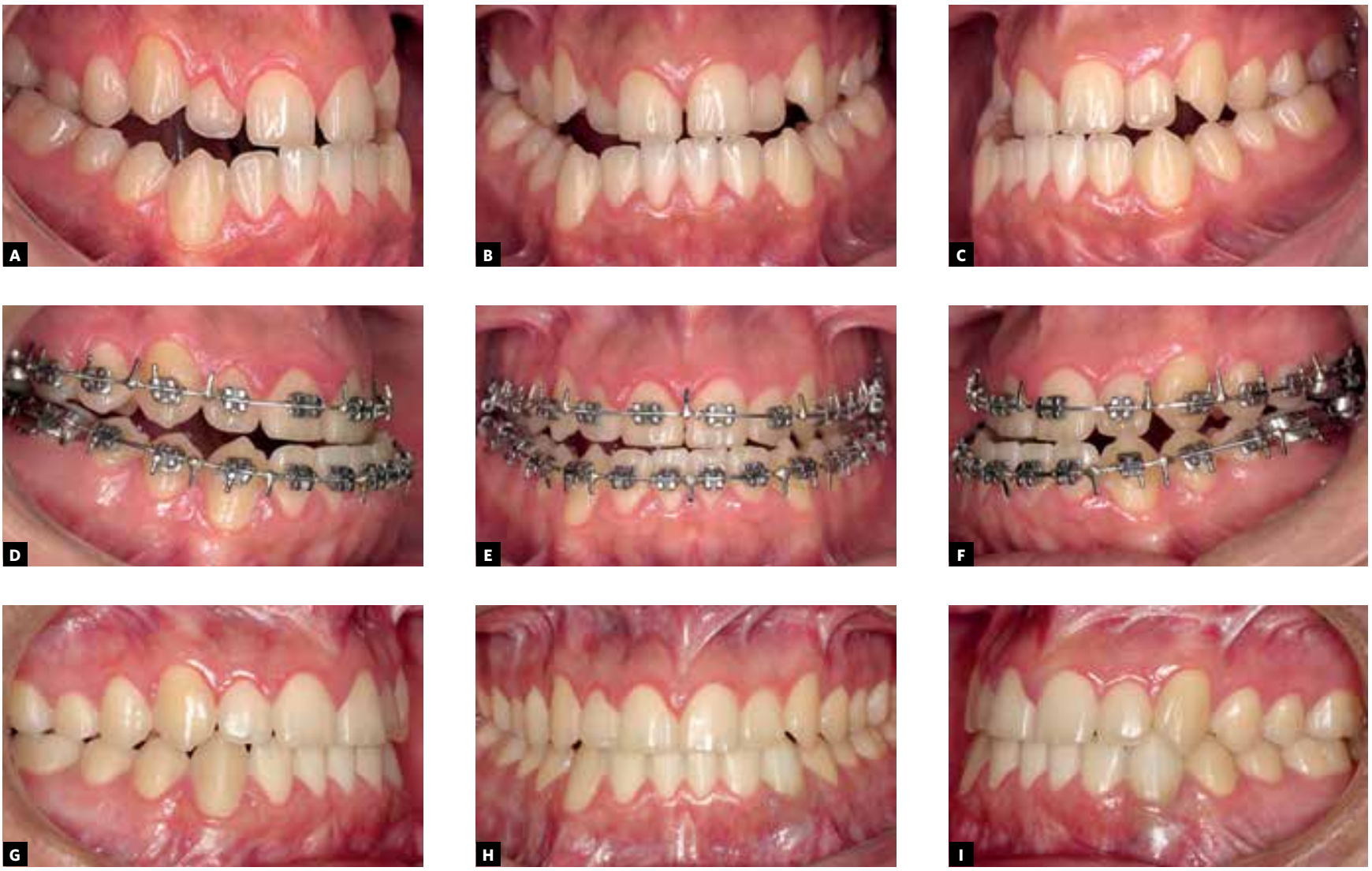

Figure 19 - Occlusal clinical follow up: A, B, C) Initial; D, E, F) after pre-operative orthodontics; G, H, I) post-operative.

showed an intraoral dental relationship of Class III, for molars and canines, lower midline shift to the left, with a slight axial offset of the upper and lower incisors (Fig 20).

The cephalometric analysis confirmed the clinical impression, showing a skeletal Class III, characterized by maxillary anteroposterior and vertical deficiency and maxillomandibular counterclockwise growth, with the occlusal plane decreased. The upper incisors were buccally inclined, while the lower were retroclined (Fig 21A).

The treatment plan chosen for the patient was the surgical-orthodontic correction of the dentofacial deformity, aiming, not only the treatment of the malocclusion, but also the facial pattern modification by surgical clockwise alteration of the occlusal plane (Fig 21B).
The patient underwent orthodontic treatment intending the preparation of the dental arches for orthognathic surgery. Alignment, leveling and decompensation of dental axial inclinations without extractions were performed.

The sequence of orthodontic treatment and surgery is shown in Figures 22-28.

\section{DISCUSSION}

Although conventional orthognathic surgery can obtain adequate esthetic results, many patients still remain - not only esthetically, but also functionally far from the ideal ${ }^{2}$. This often occurs by maintaining the incorrect relationship between points $A$ and B, i.e., by not correcting the OP and therefore the maxillary and mandibular planes. ${ }^{8}$ 

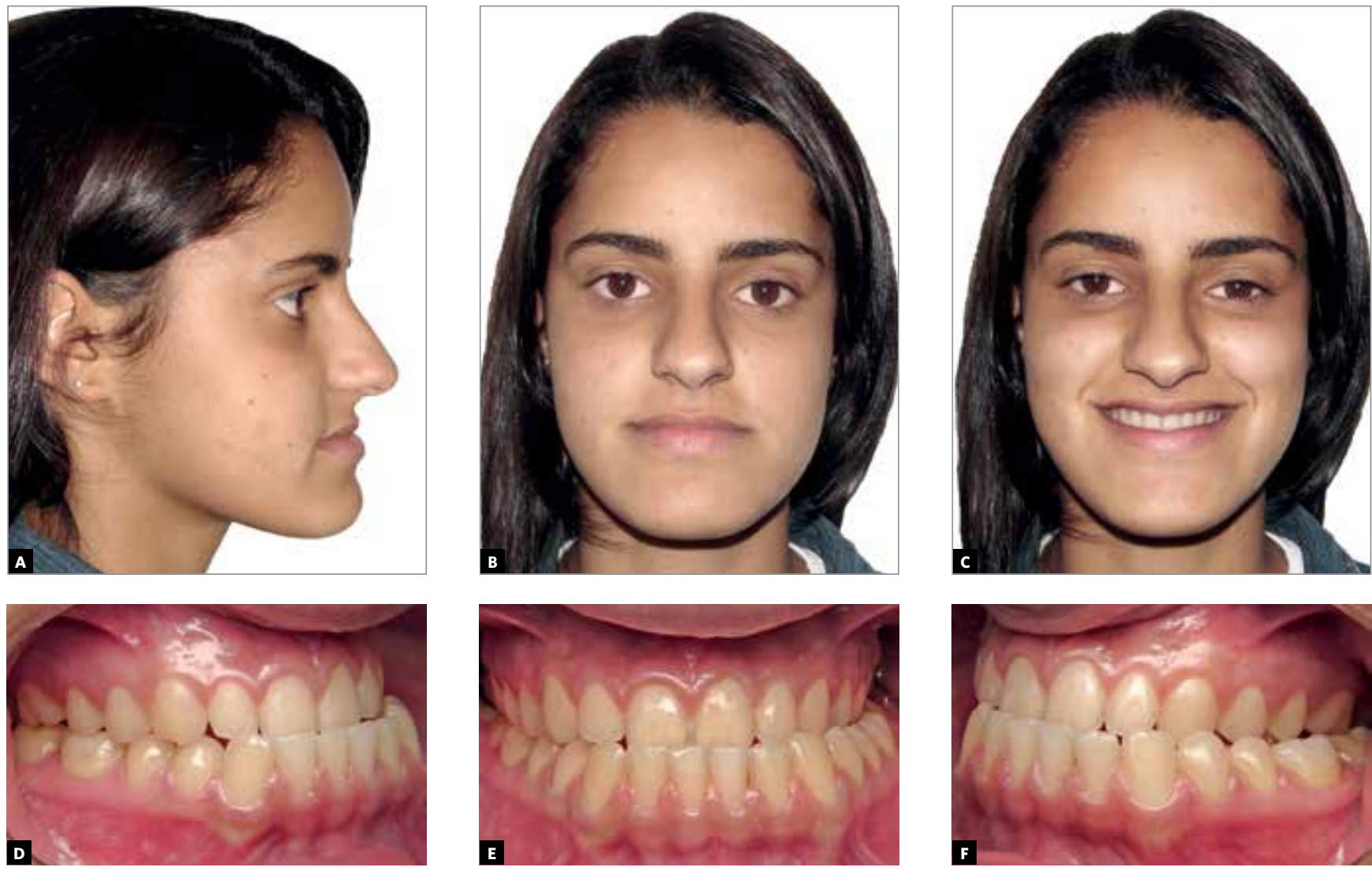

Figure 20 - A, B, C) Initial facial clinical appearance. D, E, F) Initial intraoral appearance.

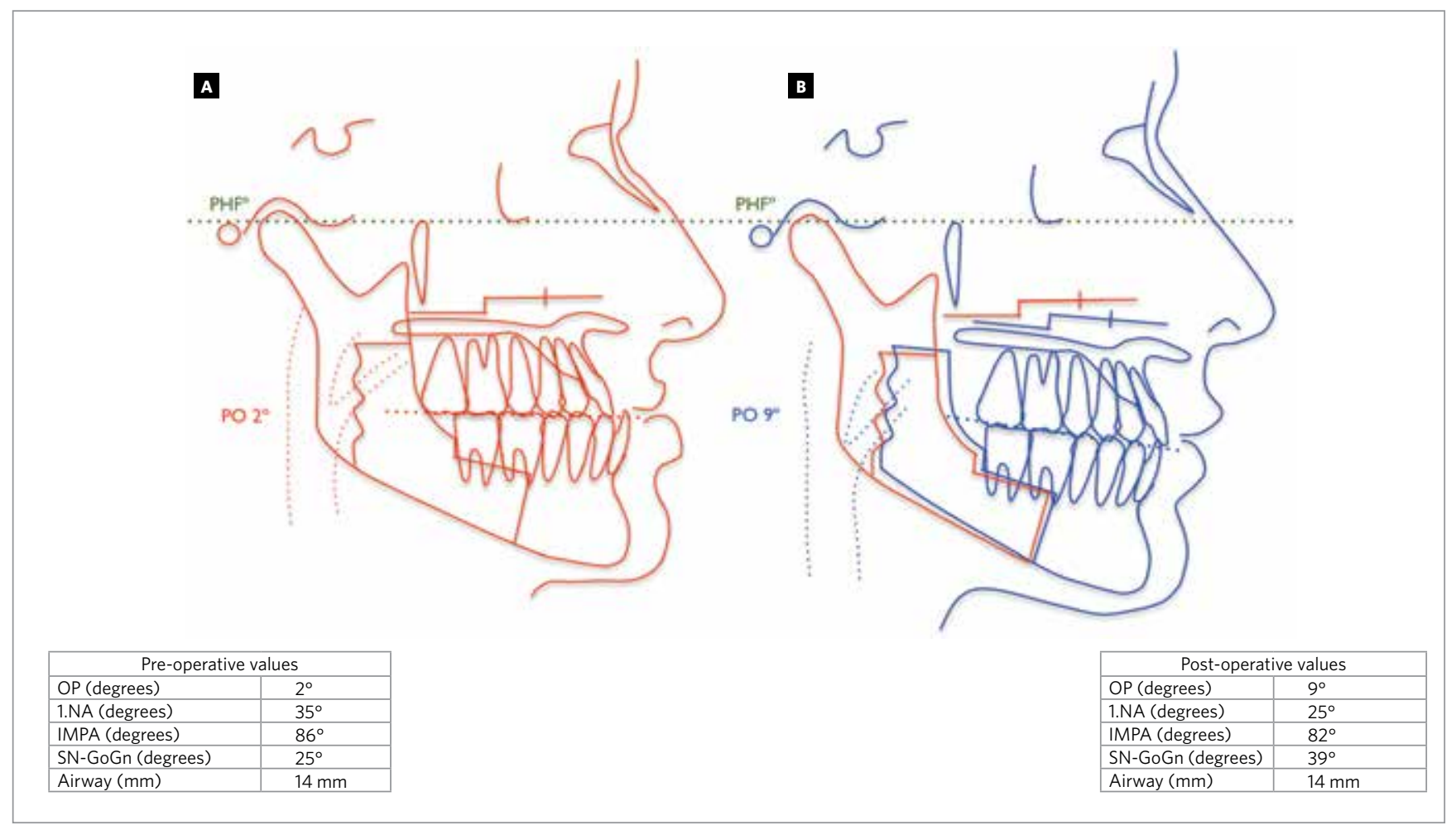

Figure 21 - Surgical correction of the occlusal plane after clockwise rotation of the maxillomandibular complex: A) Pre-operative cephalometric tracing, B) post-operative cephalometric tracing. 

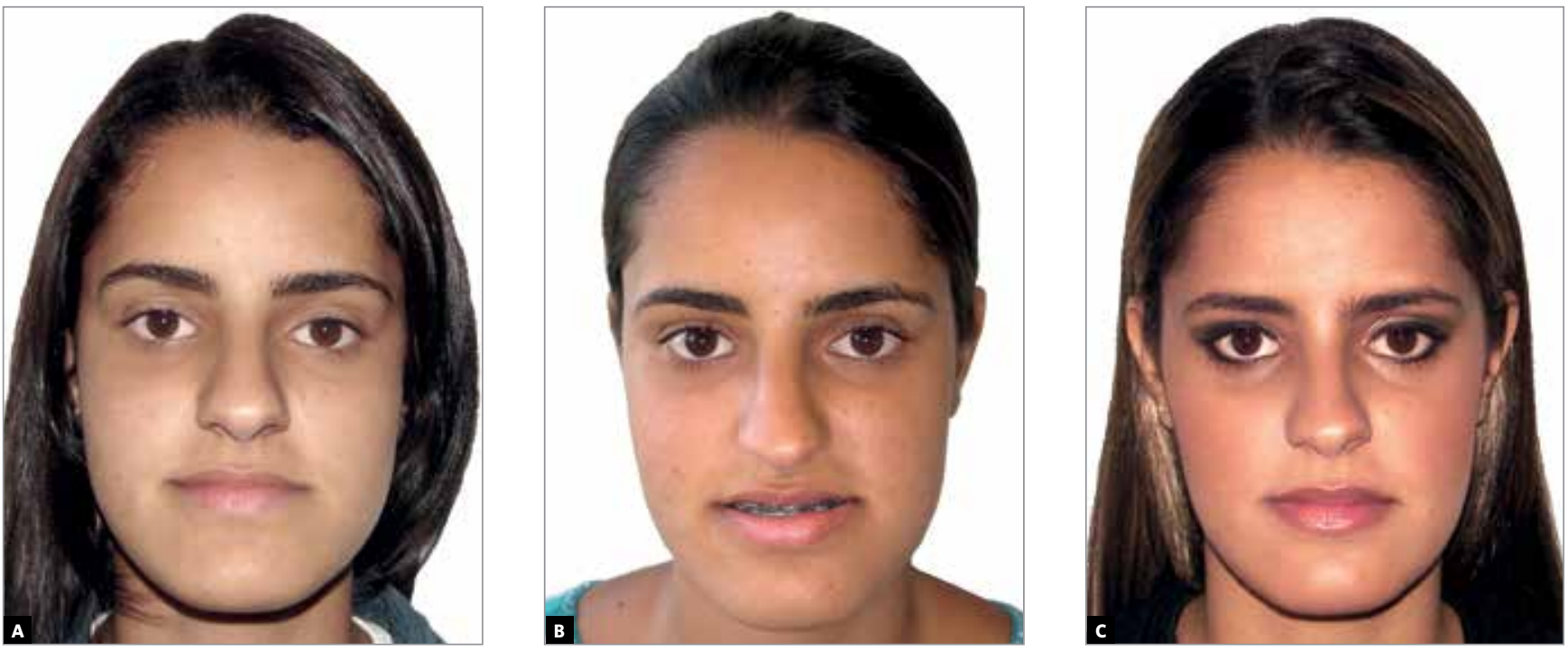

Figure 22 - Frontal facial clinical follow up with lips at rest: A) Initial, B) pre-operative and C) post-operative.
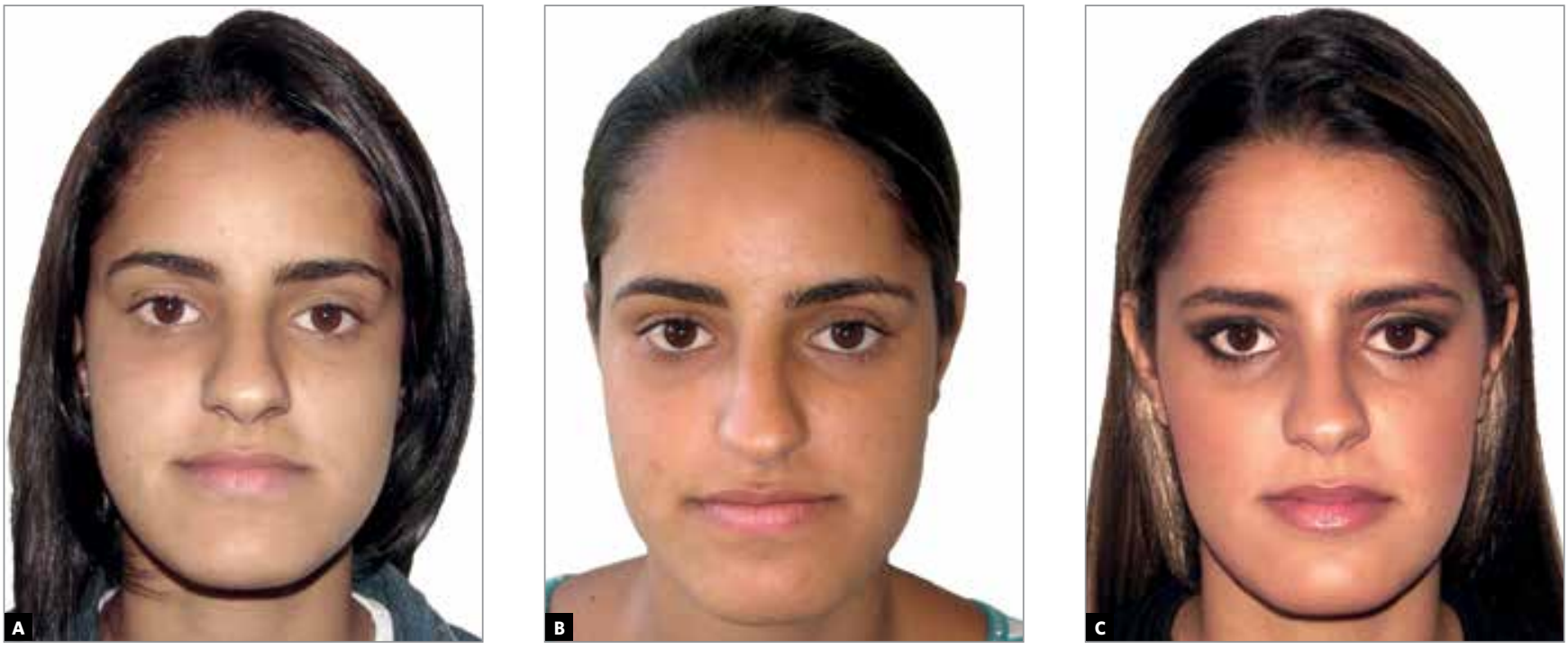

Figure 23 - Frontal facial clinical follow up with sealed lips: A) Initial, B) pre-operative and C) post-operative.
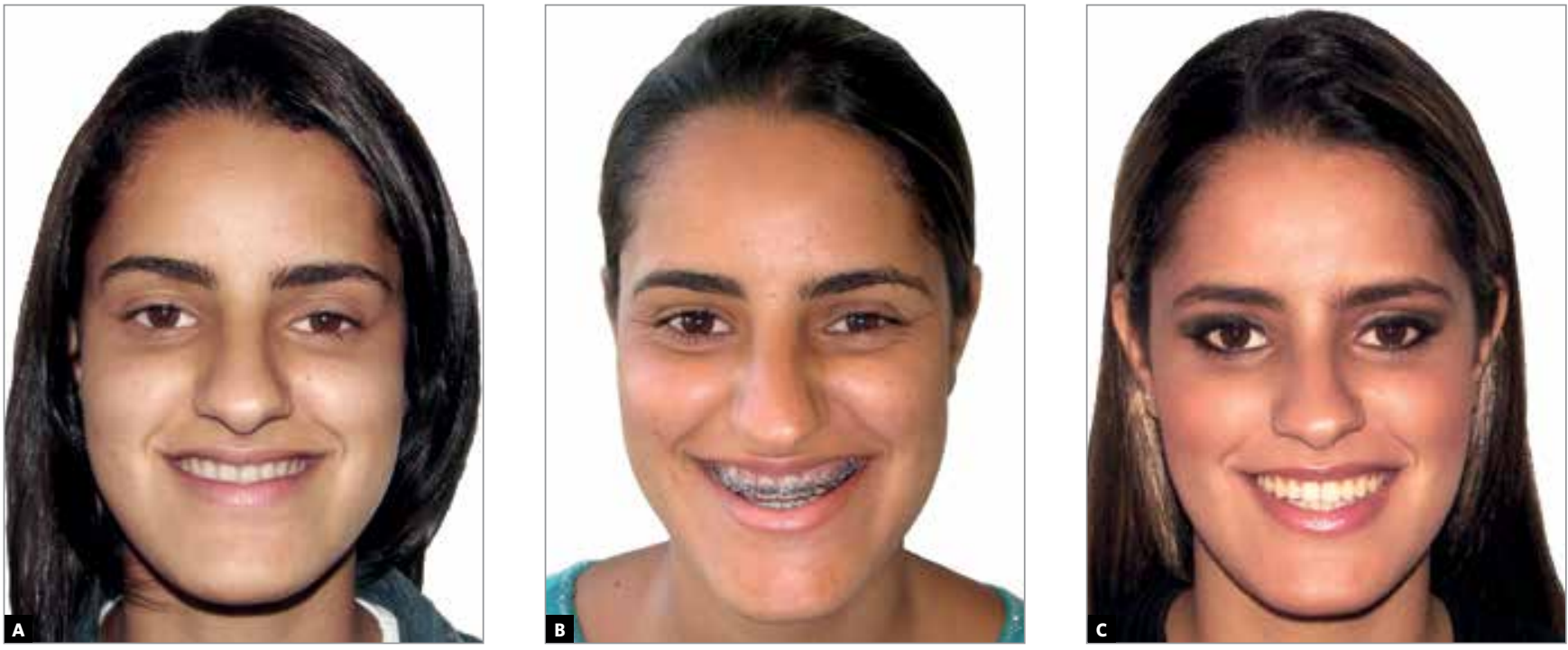

Figure 24 - Frontal facial clinical follow up smiling: A) Initial, B) pre-operative and C) post-operative. 

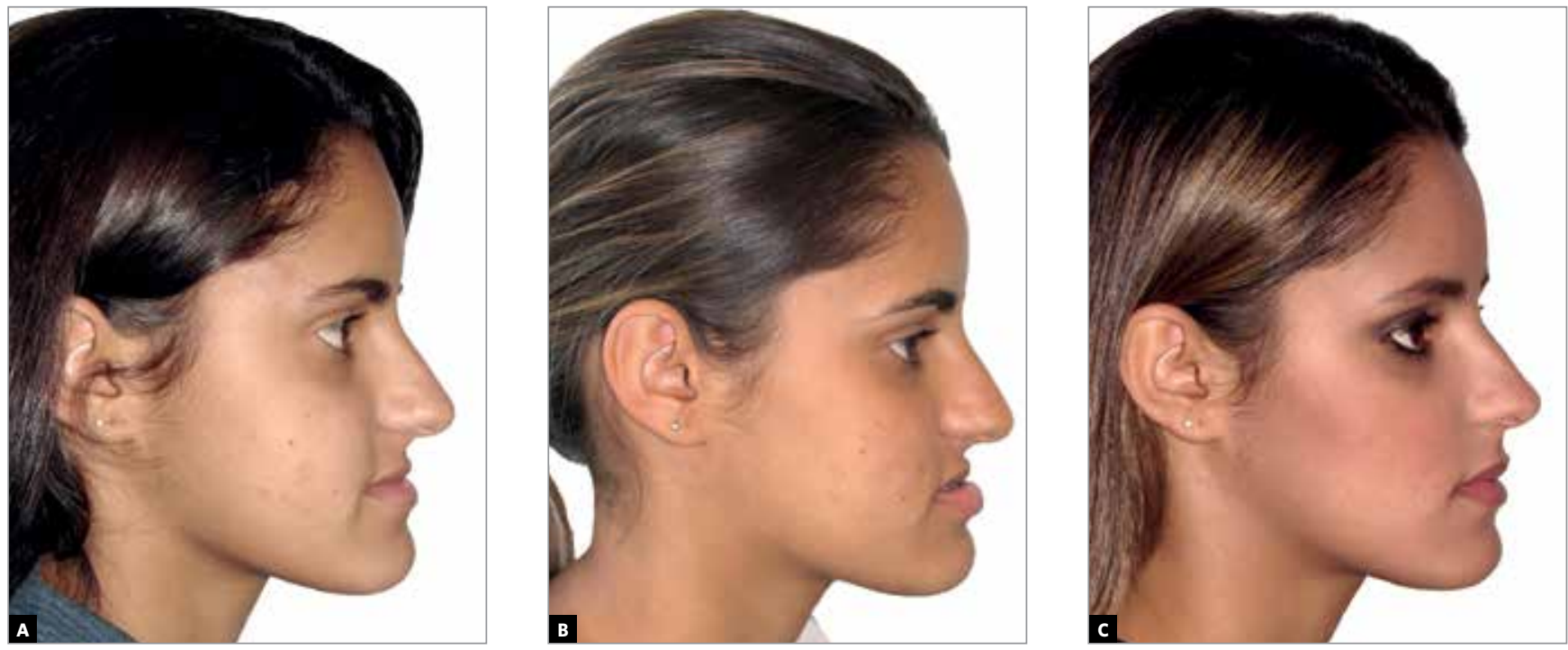

Figure 25 - Clinical follow up of facial profile with lips at rest: A) Initial, B) pre-operative and C) post-operative.
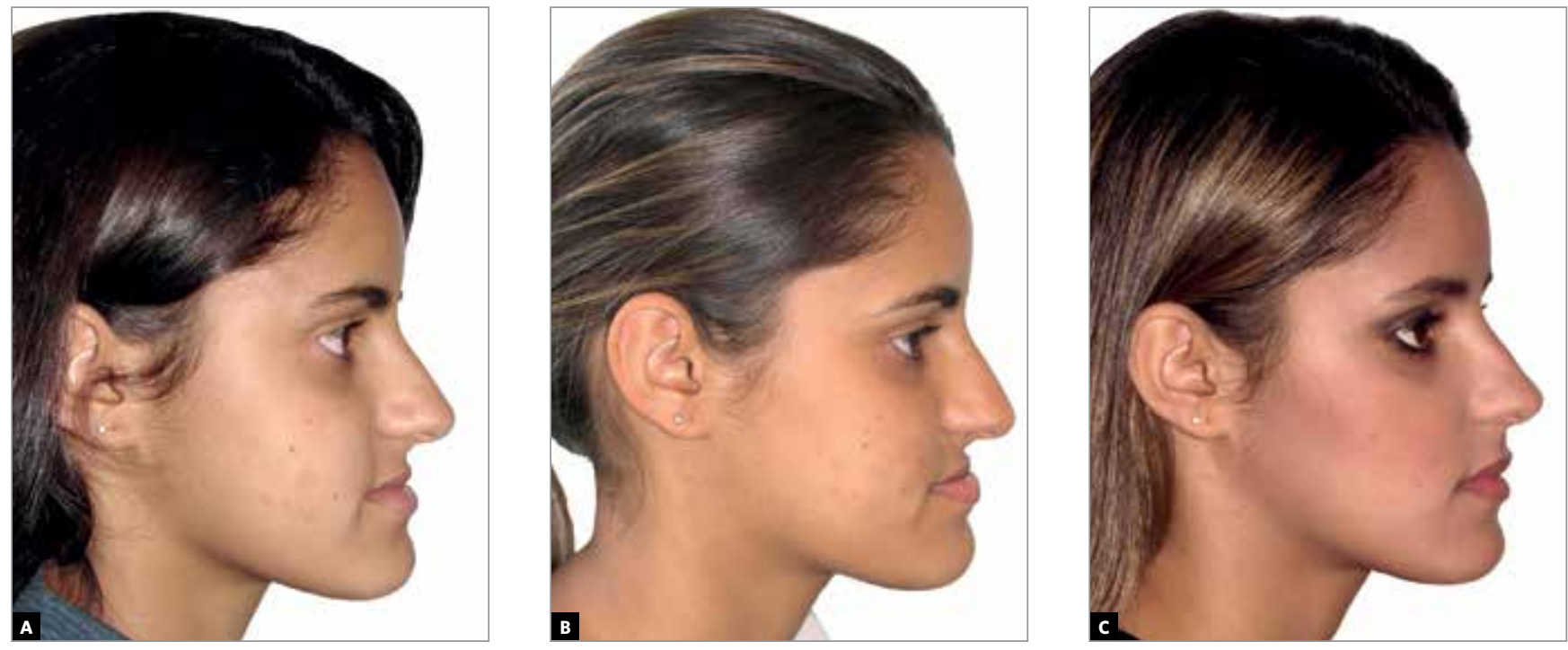

Figure 26 - Clinical follow up of facial profile with sealed lips: A) Initial, B) pre-operative and C) post-operative.
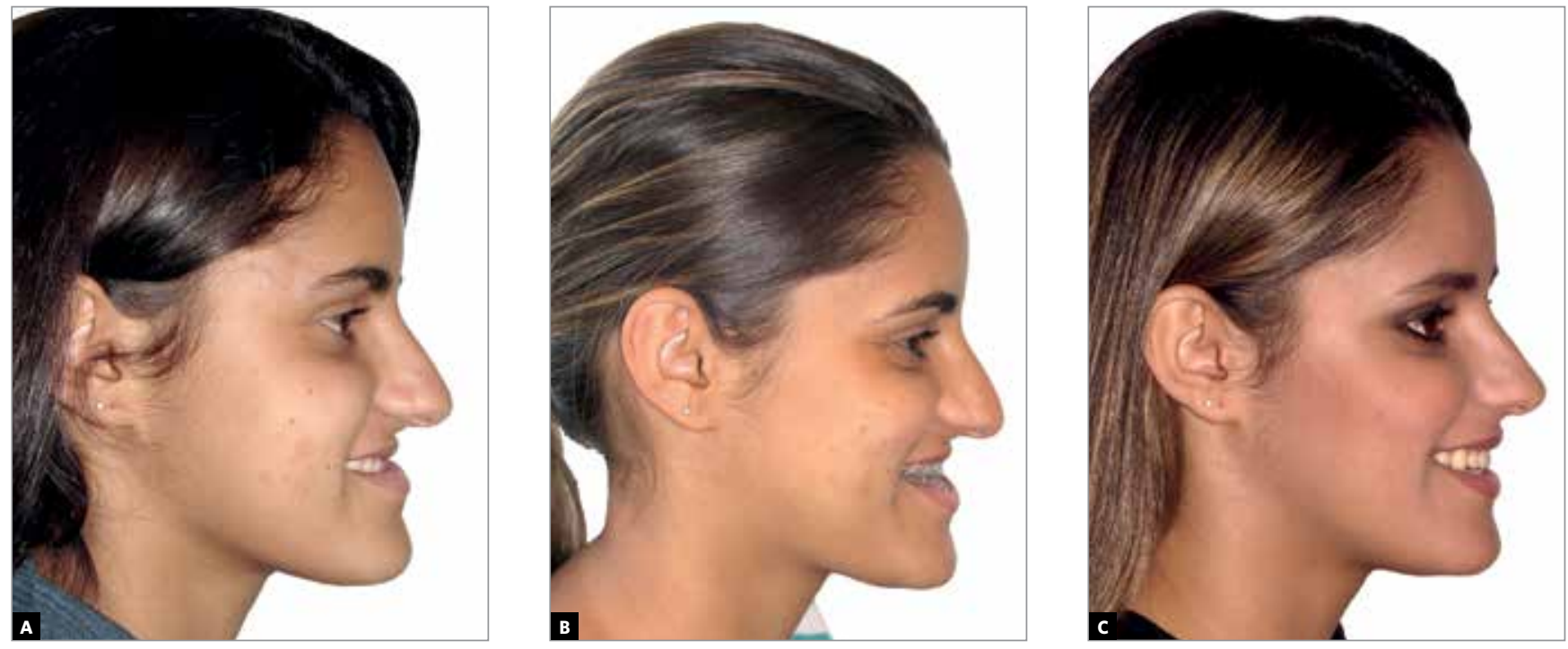

Figure $\mathbf{2 7}$ - Clinical follow up of facial profile smiling: A) Initial, B) pre-operative and C) post-operative. 

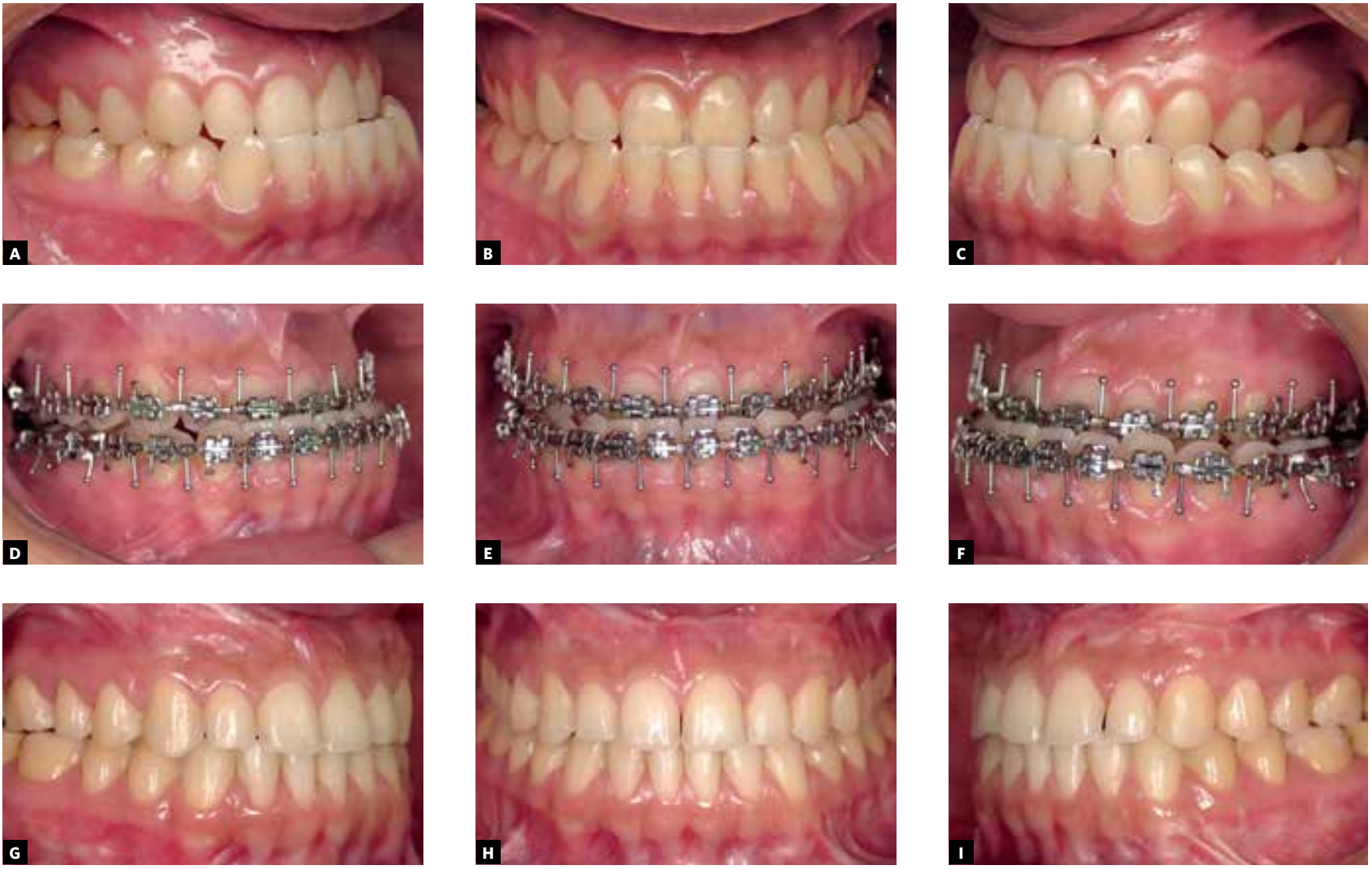

Figure 28 - Occlusal clinical follow up: A, B, C) Initial; D, E, F) after pre-operative orthodontics; G, H, I) post-operative.

As an example, the traditional orthognathic surgery for correction of vertical maxillary excess with anterior open bite was based on the Le Fort I osteotomy for intrusion (higher in the posterior region) and consequent mandible auto-rotation without performing any osteotomy in the mandibular rami. However, this mandible auto-rotation is often insufficient to achieve adequate intermaxillary relationship and great esthetic results. ${ }^{1,5,7,9}$

The use of the OP as a guide for planning an orthosurgical treatment of patients with dentofacial deformities has advantages, about which we discuss below. Besides those previously mentioned, we must take into account the functional improvement of these patients, especially in breathing pattern., ${ }^{1,10}$

A consensus already established in literature is the positive correlation between the counterclockwise rotation of the maxillomandibular complex and the breathing pattern improvement of these patients. This type of treatment, when associated with bimaxillary advancement, is considered the gold standard in the treatment of severe respiratory disorders such as
Obstructive Sleep Apnea Syndrome ${ }^{1,10}$ (which causes secondary changes in quality of life of affected patients, such as elevation of blood pressure, daytime sleepiness and loss of performance at school or at work, and even death risk). ${ }^{11}$

Another advantage of the selective surgical manipulation of the OP to be considered is the fact of not being required to obtain expressive overjets to achieve good results with surgical skeletal movement, as indicated in conventional orthognathic surgery. You can change the facial pattern of patients and obtain functional and esthetic satisfactory results in patients with Class I occlusion, as shown in cases 1 and 2 of this article. ${ }^{12}$

This fact changes the extraction standards established in orthodontic preparation for ortho-surgical conventional treatment demonstrated in clinical cases described in this article. Since there is usually no need to obtain expressive overjets, premolar extraction is limited to cases with severe crowding and exacerbated incisor inclinations, thus decreasing the total time of pre-surgical orthodontics and possible side effects in the periodontium - for example, root resorption. 
The counterclockwise or clockwise OP selective alteration in bimaxillary surgery is considered stable in patients with healthy temporomandibular joints and when using the appropriate surgical and rigid fixation technique..$^{-4,8,811,12}$

\section{CONCLUSION}

The surgical manipulation of the occlusal plane is a tool that should be considered in the initial planning stages and surgical planning of all patients with dentofacial deformities. The advantages are the possibility of changing the facial pattern regardless of the sagittal relationship of the molars and canines, the treatment of respiratory disorders of the upper airways and achievement of optimal esthetic results.

\section{ACKNOWLEDGEMENT}

We thank Dr. Pedro Bittencourt, Dr. Priscilla Esperão, Dr. Renata Viana and Dr. Maria Nicia Negrão for the teamwork and patient care presented in this article.

\section{REFERENCES}

1. Wolford LM, Chemello PD, Hilliard F. Occlusal plane alteration in orthognathic surgery - part I: Effects on function and esthetics. Am J Orthod Dentofac Orthop. 1994;106:304-16.

2. Reyneke JP, Bryant RS, Suuronen R, Becker PJ. Postoperative skeletal stability following clockwise and counter-clockwise rotation of the maxillomandibular complex compared to conventional orthognathic treatment. Br J Oral Maxillofac Surg. 2007 Jan; 45(1):56-64.

3. Chemello PD, Wolford LM, Buschang PH. Occlusal plane alteration in orthognathic surgery - part II: Long-term stability of results. Am J Orthod Dentofac Orthop. 2005;76:63-8.

4. Wolford LM, Chemello PD, Hilliard F. Occlusal plane alteration in orthognathic surgery. J Oral Maxillofac Surg. 1993;51:730-40.

5. McCollum AGH, Reyneke JP, Wolford LM. An alternative for the correction of the class II low mandibular plane angle. Oral Surg Oral Med Oral Pathol. 1989;67:231-41.

6. Reyneke JP. Surgical manipulation of the occlusal plane: New concepts in geometry. Int J Adult Orthodon Orthognath Surg. 1998;13:307-16.

7. Reyneke JP, Evans WG. Surgical manipulation of the occlusal plane. Int J Adult Orthodon Orthognath Surg. 1990;5:99-110.
8. Posnick JC, Fantuzzo JJ, Orebin JD. Deliberate operative rotation of the maxillamandibular complex to alter the A-point to B-point relationship for enhanced facial esthetics. J Oral Maxillofac Surg. 2006;64:1687-95.

9. Rosen HM. Occlusal plane rotation: Aesthetic enhancement in mandibular micrognathia. Plast Reconstr Surg. 1992;91:1231-44.

10. Mehra P, Downie M, Pita MC, Wolford LM. Pharyngeal airway space changes after counterclockwise rotation of the maxillomandibular complex. Am J Orthod Dentofac Orthop. 2001;120:154-9.

11. Esteves LS. Avaliação da estabilidade esquelética após rotação anti-horária do complexo maxilomandibular em pacientes padrão face longa submetidos à cirurgia ortognática [Dissertação]. Rio de Janeiro: Universidade do Grande Rio "Prof. José de Souza Herdy", Escola de Ciências da Saúde; 2009.

12. Gonçalves JR, Cassano DS, Wolford LM, Pinto AS, Márquez IM. Postsurgical stability of counterclockwise maxillomandibular advancement surgery: affect of articular disc repositioning. J Oral Maxillofac Surg. 2008; 66:724-38. 